treatment in this Canadian hospital is said by those who conduct the treatment to be in a better condition for the miller than it would be if it had come in as regular normal wheat, the reason for this claim being found in the fact that when the wheat has recovered from its illness it has lost a non-essential part of its outer coat which would have to be removed anyway when put through the regular milling process. So tar as I know, none of this wheat is ground for flour in the United States, all of it going to Europe, mainly to Eng. land, or to various Canadian towns and cities in the lant or to vallous Canadian towns and eastern part of the Dominion. Whether the millers of the United States would consent to use the flour
which had passed through a similar hospital treatment which had passed through a similar hospital treatment on this extensive scale or not, is a matter of question,
though in seasons of shortage it might be found practicable, provided the kernel was up to the proper grade. There can be no question, however, as to the

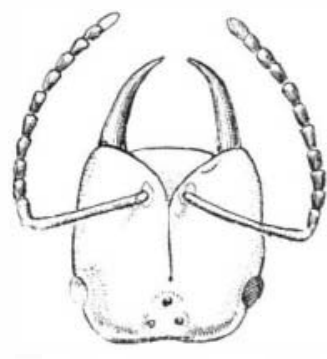

HEAD OF WARRIOR ANT. bowing pointed and curved mat

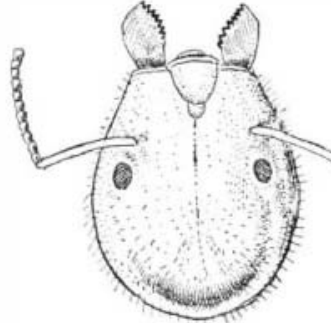

HEAD OF WORKING ANT sho on woRTing axT. interest sucl a hospital in this country would have for such faimers as suffer loss from any one of the for such faimers as suffer loss from any one of the
various diseases which the Canadian hospital treats.

\section{SOME NEW FEATURES IN ANT LIFE.}

The recent discoveries of Wasman, Florel, Belt and others, added to the wonderful results of the investigations made a few years ago by McCook, Moggridge and Bates, have deservedly awakened a new interest in everything connected with the lives and habits of ants. The remarkable evidences they exhibit of som thing which, notwithstanding its limitations, seem akin to human intelligence; the perfection, as compared with other insects, of its physical structure; the greater porportion borne by the brain to the rest of the body; and its wonderful social life, so much more highly developed than that of the bees or of the wasps, have inclined those the bees or of the wasps, have inclined those
who study it the closest to believe that, makwho study it the closest to believe that, making allowance for the great inferiority of the class of invertebrates, the Formicadæ certainly hold among invertebrates a rank commensurable with that sustained by Primates, including man, among vetebrates.

Taking into account the comparatively enormous masses of brain matter belonging to a number of large animals which exhibit marked degree of incogitance, and the intelligence manifested by members of this division of Hymenoptera, the claim made by Darwin that the anterior ganglion in the head of an ant constituting its brain "is the most marvelous atom of matter in the world," is justified.

The hippopotamus, in the tremendous lapse of time which has attended its evolution, has learned scarcely more than to fulfill the sim plest and most obvious requirements of nature while the ant has developed competence that in some instances has anticipated mankind in acquiring arts and industries indispensable to the well-being of social life, and a practical wisdom in adjusting the conditions which govern them in their association in communities quite beyond anything mankind has yet been quite beyond any

It is interesting to notice how diverse are the methods adopted by invertebrate intelligence frorn that of man in attaining a desired result. Man looks entirely to the outside world about him for the means of accomplishing his purposes; insects, on the contrary, drawing upon the resources of their own natural constitutions, often adapt themselves to the conditions and requirements of their lives by ditions and requirements of their lives by structural modifications. For instance, men make the tools they require for carving or for
digging, insects grow them; vessels being digging, insects grow them; vessels being needed as receptacles for liquid food, man learns the art of the potter, but the curious honey ants (Myrmecocystas melliger, of Llave; M. nortusdeorum. McCook; Camponotus in fatus, Lubbock) transform themselves into liv ing bottles, to which the working members of the commune resort for refreshment

The tools of insects, exquisitely fashioned and finished, are much more perfectly adapted for the purposes they serve than are any con- trived and manufactured by human beings, but there

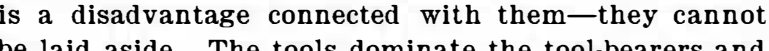
de. The tools dominate the tool-bearers and check development in any direction not connected with their use.

This leads to the extreme specialization we find among insects. Species or varieties among species be come mere functional organs in the sense that the liver or the kidneys are such, devoted and limited to some one particular use, and in some cases scarcely retaining a suggestion of possible action in any other. The egg producer, the queen of the termites, although she possesses the usual number of limbs belonging to her species, is totally incapable of locomotion, as are the living bottles of the honey ants. The queen lay eggs; she can do nothing else; the living bottles stor up and yield food to other members of the formicary, and are as incapable of performing other uses as if they were mere lifeless cells in a honeycomb.

Among the Formicadæ this tendency to specialization has resulted in establishing species limited to particular industries or to particular methods of living. Some species of slave-making ants, for instance, conine themselves so entirely to military affairs, and have so entirely lost the arts of peace and efficiency in domestic matters, that they are not only obliged to depend upon their s!aves to care for the young in the formicary, but to have the food placed in their own warlike mouths, and would starve in the midst of plenty were this not done.

The mandibles of these ants, Polyergus rufescens The mandibles of these ants, Polyergus rufescens
and P. lucidus, the former a European, the latter an American species, are entirely unfitted for work. They can neither crush, cut nor saw; but, being sharply pointed and curved, they make most serviceable weapons; with them in attacking an enemy, Polyergus seizes the head of her foe between the points of these curved poignards and penetrates the brain at once.

It sometimes happens, however, that either the conditions are such that the instincts common in a greater or less degree to all species of Formicans cannot be followed out in any ordinary manner, or that Nature has failed to provide in the structural developmen of the insect proper appliances necessary to its domestic economy.

Such instances, when they occur, are not only exremely interesting, showing as they do the Formicad capable of utilizing in the most ingenious ways what

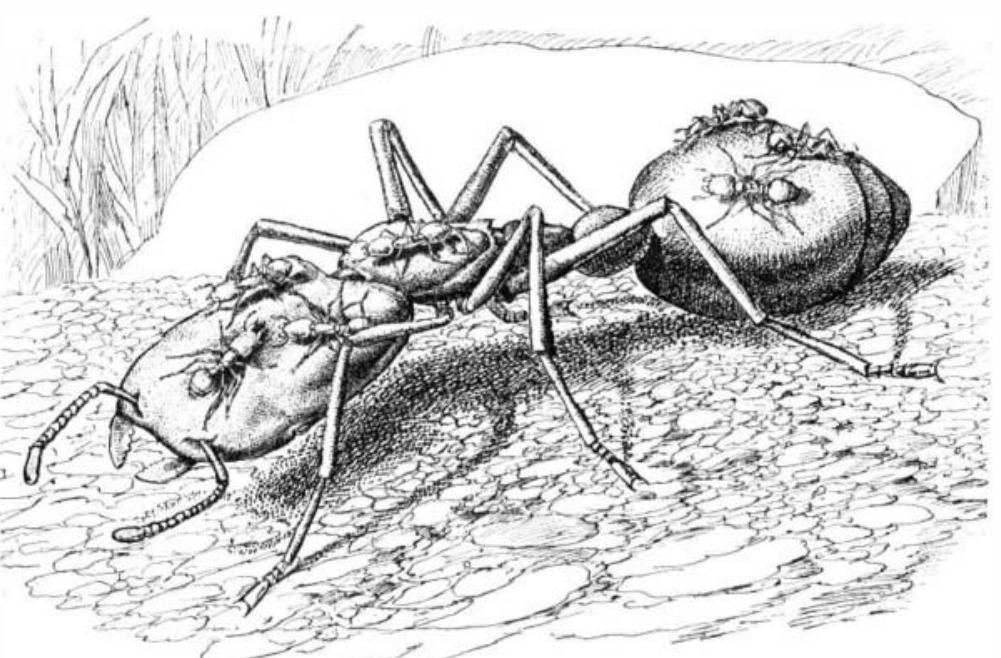

STATE ELEPHANT OF THE PHEIDOLOGETON-LARGE WORKER CARRYING THE SMALLER ONES.

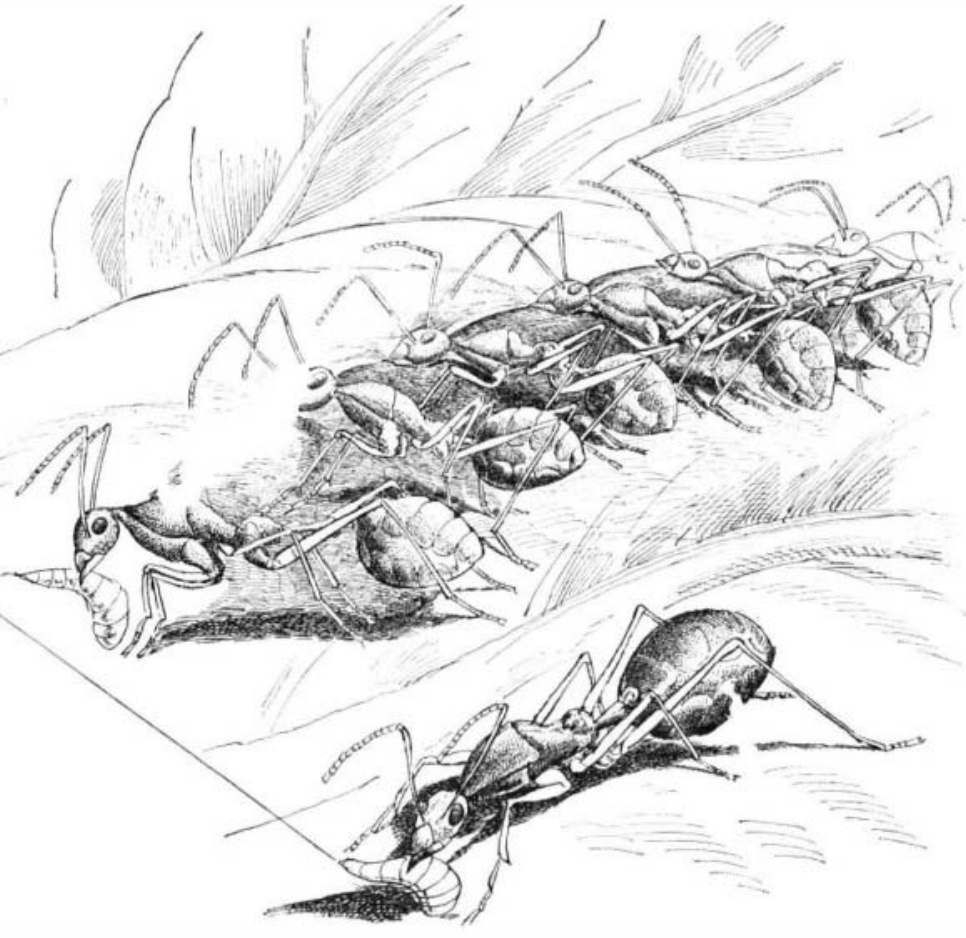

WORKERS HOLDING LEAVES IN PLACE WHILE OTHERS USE LARVE TO BIND AND CEMENT THE LEAVES. ever can be made to answer their purposes, but the extraordinary and unexpected manner in which this is done is apt to awaken in the observer, as if he saw some comical trick performed, a mingled sense of admiration and amusement. A number of ants among those of very different species are distinguished by possessing relatively large heads, the use of which is extremely problematical. 'The workers of the East Indian Pheidologeton diversus, for instance, spiteful that bite venomously, have among giant soldier ants, a hundred times as large as them



NEST OF THE TREE ANT, INDIA.

selves, and it would naturally be supposed that these big creatures with enormous heads would prove formidable defenders of the formicary, while the truth is that, so far from this being the case, they cannot bite at all, even when provoked to do so.

And yet the smaller members of the Pheidologeton commonwealths find a use for the great creatures. Numbers of them may often be seen riding about, a human beings do upon elephants, upon the backs and heads of their gigantic confreres. Even this use, however, does not account for the disproportionately large heads of the giants. But the Colobopsis ants, which burrow in branches, seem to have discovered how to profitably employ the big-heads among them. They are placed at the entrances of the Formican dwellings, their great heads fitting in and filling the dorways. As a worker be longing to the household approaches she is recognized by "the animated and intelligent front door," which draws back sufficiently to admit the entrance of its friend and then resumes its double office of sentry and of bar-

The Eciton are the Arabs of the ant tribes, always at war with all other animals, with $n$ settled places of abode, but ever wandering in journeys that have no end. Yet in their temporary resting places the necessities and in stincts common to the whole Formican family impel these nomads to build habitations which conform to the character and style of the fixed and permanent abodes of ordinary ants. As, however, both the time and natural apparatus for digging possessed by the latter are wanting to excavate galleries and apartments necessary for feeding and sheltering larvæ and pupæ, these remarkable animals overcome the difficulty in a most astonishing manner by con structing living habitations, using their own bodies as building materials. Belt writes: "They make their temporary habitations in hollow trees, and sometimes underneath large fallen trunks that offer suitable hollows. A nest that I came across in the latter situation was open at one side. The ants were clustered together in a dense mass, like a great swarm of bees hanging from the roof, but reaching to the ground below. Their innumerable long legs looked like brown threads binding together the mass; which must have been a cubic yard in bulk, and contained hundreds of thousands of individuals, though many moving columns of ants were outside, some bringing in pupæ, others the legs and the dissected bodies of various insects. I was surprised to see in this living nest tubular passages leading down to the center of the mass, kept open just as if it had been formed of inorganic material. Down these holes the ants that were bringing in booty passed with their prey. I thrust a long stick down to the center of the cluster and brought out, clinging to it, many ants holding larvæ and pupæ."

But the most amusing instance of the man ner in which an ant left by Nature to her own devices overcomes a difficulty is perhaps that 
of the Oecophylla smaragdina. This ant, one of common occurrence in Eastern Asla, form shelters by bending the edges of the leaves of the trees upon which it lives and fastening them together. The adult ant possesses noth ing with whic nto the required position; but its larva is furnished with glands that secrete an abundance of adhesive, gelatinous substance, by the aid of which it forms its cocoon, and these intelligent insects actually make animated mucilage brushes of their larvæ in order to effect their purpose. A number of the ants, seizing the edges of the leaves in their mandibles, bring pures there while other ants, each one of which bears a larva in its jaws, apply the mouths of the larvæ to such parts of the leaves as require to be cemented together, and induce their offspring to disgorge as much sticky material as they find necessary to accomplish the desired result.

Such instances as these of a knowledge of cause and effect, a seemingly conscious adaptation of means toward a desired end, and what may, perhaps, be called audacious ingenuity in devising methods of overcoming difficulties that at first sight seem insuperable, argue faculties which it is difficult to differentiate from sense and reason.

\section{THE COOPER HEWITT LAMP.}

The most recent as well as the most interesting development in electric lighting has lately been brought about by Mr. Peter Cooper Iewitt, son of Ex-Mayor Hewitt of this city, as the result of long-continued and untiring as the result of long continued and untiring exertions on his part. This remarkable inven-
tion was recently described by $\mathrm{Mr}$. Hewitt at a "Conversazı " at the Columbia University during an exhibi.. $n$ of recently invented electrical devices. The high-power electric lights exhibited by Mr. Hewitt were on a new principle, a gas being used as the illuminating medium instead of the usual filament. Several of these lamps are shown in the half-tone and line engravings which we publish. These lamps were engravings which we publish. These lamps were
all experimented with by Mr. Hewitt, and the all experimented with by $\mathrm{Mr}$. Hewitt, and the
light produced by some of them was truly remarklight produced by some of them was truly remark-
able, since it compared favorably with the arc light. The color of the light emitted from these



Fig. 8.



Fig. 11.

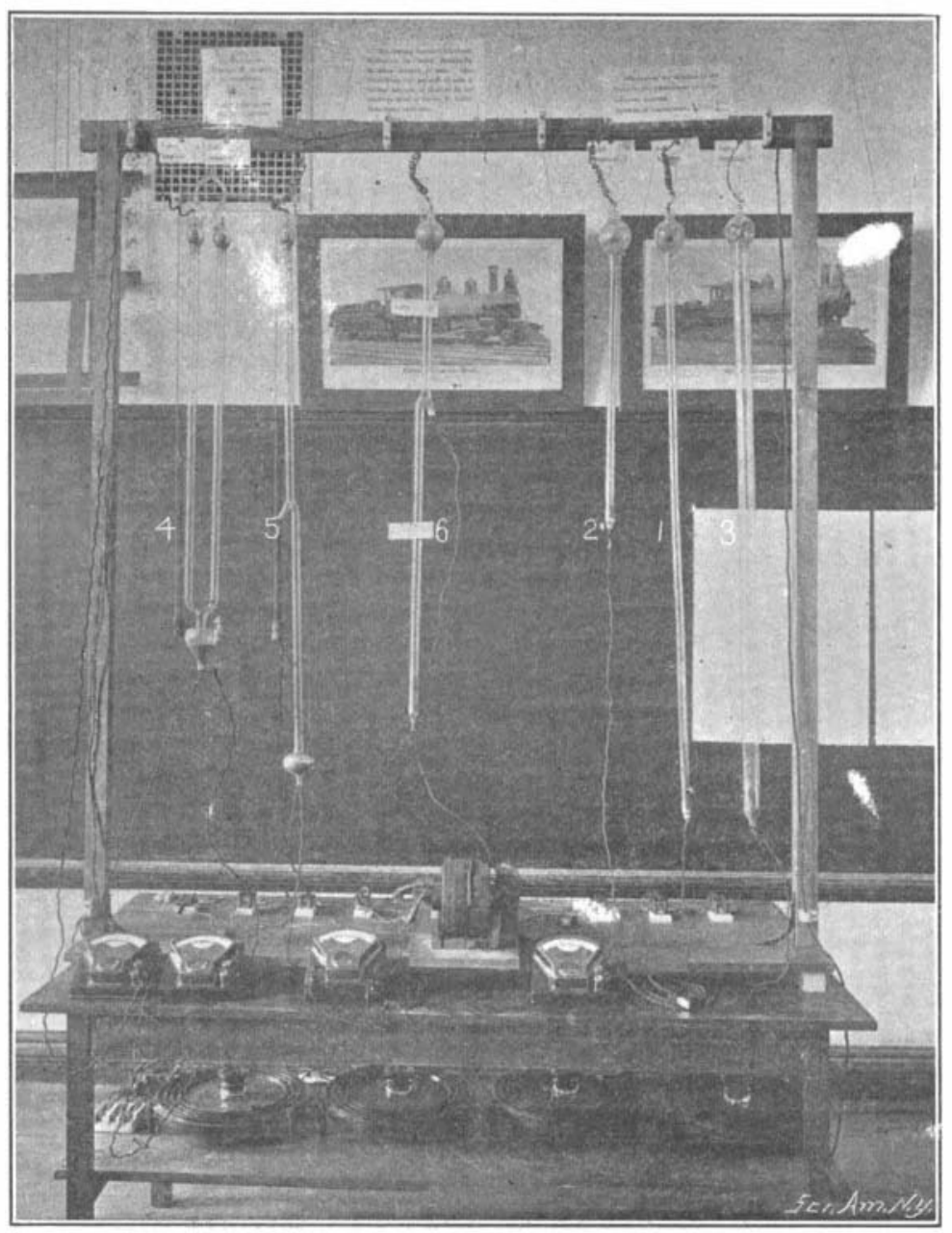

Flo. 1.-Length, 54 inches ; diameter, $\$ 4$ inch; volts, 90 . Fig, 2.-Length, 27 inches ; diameter, 34 inch; volts, 46. Fig. 3.-Length, 54 incheo; diameter. 36 inch; volte, 54 Fig. 4.- In left-hand circuit, volts, 62 ; amperes, 4 ; obm8. 15.5. In right-band circuit,
volte, 64; amperes, 2; volte, 64; amperes, 2 ; obms, 32 . Fig. 5 . - In upper balf. volts, 35 : amperes, 1.25 ;
ohms, 20. In lower balf, volts, 47 ; amperes, 35; ohme. 13.4. Fig. 6. - In upper portion, vclts, 28 ; ampe.es. 3 . In lower portion, volts. $44 ;$ amperes, 2.98 .

THE COOPER HEWITT ELECTRIC VAPOR LAMP EXHIBITED AT COL UMBIA UNIVERSITY.



Fig. 7.

lamps depends mainly upon the gas used for the filling of the tubes. Some of the tints are objectionable, but they may be varied by changing the character of the gas. The remarkable feature of these lamps is that under the proper condition

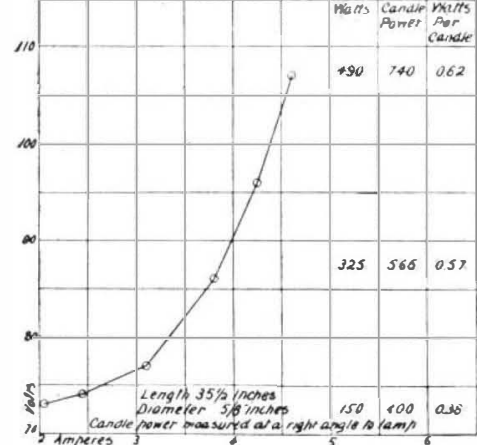

Fig. 9

of temperature and exhaustion they may be operated by a direct current from any circuit of sufficient voltage. The light obtained has a most astonishin brilliancy and is perfectly steady. We understand that efficiencies as high as from 0.5 to 0.32 watt per



Fig. 12 candle power have been obtained. Mr. Hewitt has made a special study of the laws of conductivity of vapors, and has ascertained many curious facts in regard to their behavior as conductors in his lamp tubes.

By reference to the half-tone engraving it will be seen that the lamps are exceedingly simple, being merely tubes with electrodes sealed in either end, in some cases surrounded by mercury, which supplies the vapor which fills the tube and becomes luminous on the passage of the current. These tubes are lighter by an ordinary direct current of from 100 to 200 volts, after being started by an impuls sent through a Wehnelt interrupter. The vapor tube acts like a conductor with a re sistance which varies inversely as the current flowing through it.

The lamp is interesting on account of it; great power and extreme simplicity. The many curious facts in regard to this lamp and othei electrical phenomena discovered by Mr. Hewit: would make a very interesting volume.

We take pleasure in publishing herewith the following

NOTES ON TIIE COOPER HEWITT LAMP, BY PETES COOPER IIEWITT.

The purpose of the exhibit which I had the honor to present at Columbia University, be fore the American Institute of Electrical En gineers, on April 13, 1901, was:

First.-To demonstrate that light can be pro duced from a gas or vapor in great quantily by means of the electric current and in the quantity desired.

Second.-To demonstrate that light can be produced from direct-current low-voltage cir cuits, by means of a gas or vapor.

Third-To show that this light is extremeiy efficient

Fourth.-To illustrate laws of conduction of the electric current by gases or vapors, and to show by experiment the effect of current on a conducting vapor or gas and the effect of variation in density of the conducting vapor on the current passed.

Fifth.-To exhibit the electrical phenomena at the joint of the negative electrode with a gas or vapor.

sixth.-To exhibit electric vapor or gas lamps of very high efficiency.

Seventh.-To demonstrate that change in the color of the rays of light proceeding from a gas or vapor lamp of this character can be brought about by means of certain material.

Eighth.-To show, by means of curves, that the resistance of a particular vapor in a lamp can be made to vary in a predetermined manner within wide limits by varying the proportion of the vapor subjected to the current and the heat-radiating ability of the lamp.

The demonstrations actually made are illustrated by

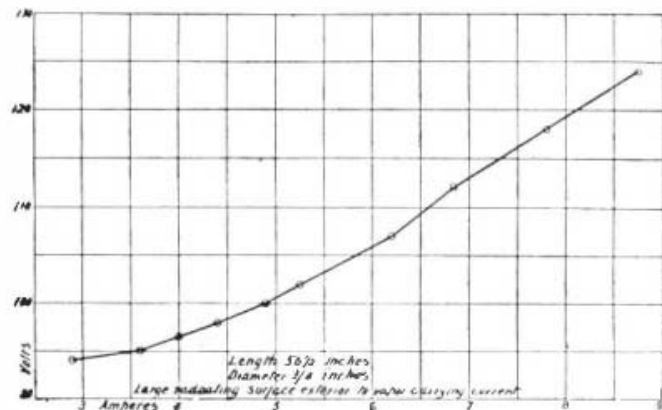

Fig. 10.



Fig. 13 